\title{
5
}

\section{QILT: An Approach to Faculty Development and Institutional Self-Improvement}

\section{Mike Laycock}

University of East London

In a climate of increasing emphasis on quality assurance and extra-institutional quality scrutiny, the author argues that faculty developers have a role in encouraging an enbancement-led culture. Faculty ozenersbip of, and responsibility for, continuous quality improvement can belp to provide an engagement with leaching and learning issues and may belp to overcome resistance and mistrust. At the University of East London, UK, an enabling, whole-institutional framework called QILT (Quality Improvement in Learning and Teaching), whereby faculty create and implement funded improvement plans, has belped to generate this culture.

\section{INTRODUCTION}

The responsibility of universities for quality and standards has placed great emphasis on the monitoring and review of performance for the purposes of accountability. During 1993, the University of East London, UK, undertook a major review of its internal quality assurance procedures, particularly those associated with the academic review of courses. Two working parties were established to consider the processes of Subject Review and Teaching Review. The latter produced a policy document that radically re-defined the university's approach to quality assurance by emphasizing the importance of quality improvement rather than traditional notions of review. It was felt that quality assurance alone was of dubious value in providing a model to respond to, or to create, change and improvement. 
This emphasis on quality assurance has been redressed at the University of East London (UEL) by a complementary, collective responsibility for improvement. This whole-institutional model of Quality Improvement in Learning and Teaching (QILT) was introduced in 1994/5. QILT is a process of continuous quality improvement that involves the creation of funded improvement plans by staff/student groups, the implementation of the plans, and the formative and summative evaluation of progress.

Most faculty development is about change. Continuous reflection on, and adaptation to, changing circumstances and the development of a culture of self-evaluation and self-improvement will be the hallmarks of a mature and responsible institution in its pursuit of quality improvement. However, the present arrangements for the external scrutiny of quality in higher education, it could be argued, have emphasized a static rather than transformational concept of quality. Given the range of internal and external pressures on higher education, it is likely that qualitative indicators will need to be developmental. As Yorke (1994) has succinctly put it:

Higher education will probably need to be steered more positively towards the future than a coxless four, in which the rowers face backwards while moving forwards on the assumption that the competition lanes will not curve away from the straight (p. 7).

For some years, observers of both UK and US higher education systems have directed attention to the problems inherent in "accountability-led" regulatory frameworks for the assurance of quality. Pressures on institutions have arisen in the UK principally through government policy. At the subject level, formal accountability is exercised through a cycle of reviews of teaching quality. The Quality Assurance Agency for Higher Education (QAAHE) currently requires each subject area to undertake a self-assessment exercise every five years in the following "core areas of provision":

- Curriculum design, content, and organization

- Teaching, learning, and assessment

- Student progression and achievement

- Student support and guidance 
- Learning resources

- Quality management and enhancement

At the institutional level, QAAHE undertakes a "continuation" academic quality audit. A number of UK universities are now preparing for, or have undertaken, the continuation academic quality audit under new guidelines prepared by the QAAHE. The emphasis for the audit is placed firmly on the issue of standards. There is little doubt that con-cern about standards within the regulatory framework derive from government anxiety about the movement from an elite to a mass higher education system. Unsurprisingly, some have suggested that there has been a withdrawal of trust in higher education's ability to manage that transformation without loss of standards. As Trow (1996) has described it:

In transforming that elite system of higher education into a system of mass higher education, the British government in the past decade has gone to such lengths to deny the relevance of such claims to trust, and to subject the whole of the system and its members to what can only be seen as a mass degradation ceremony, involving the transformation of academic staff-scholars and scientists, lecturers and professors alike-into employees, mere organizational personnel (p. 318).

Similarly, Jackson (1997) has suggested that:

The current arrangements, which emphasise public accountability through publication of results of external quality reviews, are seen by many academics to penalise openness and honesty and reward secrecy and camouflage of problems. A regulatory regime, which was focused on development, would not penalise institutions for being self-critical (p. 172).

Likewise, Trow (1996), in commenting on the accreditation process in the US, has argued that:

To a considerable extent, external academic accountability in the US, mainly in the form of accreditation has been irrelevant to the improvement of higher education; in some cases it has acted more to shield institutions from effective monitoring of their 
own educational performance than to provide it; in still other cases it distinctly hampers the efforts of institutions to improve themselves. It encourages institutions to report their strengths rather than their weaknesses, their successes rather than their failures-and even to conceal their weaknesses and failures from view (p. 316).

It is against these increasing pressures for accountability and professional mistrust that faculty developers must try to encourage faculty development. All faculty developers recognize the complexities of their work in attempting to discharge whatever function they have set for themselves in their university. Though many different roles and approaches have been identified (in the UK see, for example, Gosling, 1996), the fundamental effort is towards encouraging faculty to reflect on, review, and implement changes to their teaching, learning, and assessment practices and approaches to curriculum development. Faculty developers also know that in some areas of their institutions they encounter resistance to their work. The Quality Improvement in Learning and Teaching (QILT) program at the University of East London has become a means of creating a culture of engagement with faculty development across the whole university and a vehicle for transformational change towards a "learning organization."

\section{WhaT Is QILT?}

The QILT Program is coordinated by the university's Educational Development Services (EDS) and forms a major plank of its faculty development program. Some might argue that to try to "capture" the quality debate through faculty development is unwise. Since the university's EDS became the locus of the program, it has clearly signaled that QILT is part of the quality agenda of the university. There are, of course, risks that associating it with that agenda will prompt unfavorable reactions from faculty. But many faculty developers encounter resistance to their work, whether or not such an agenda is made explicit.

Educational Development Services has created an enabling framework to facilitate faculty development. Each department/subject team undertakes a regular and iterative cycle of quality improvement. The team is relatively organic and dependent on the priorities identified. It has faculty and student involvement but may also include administrative, technical, and learning support staff. 
The cycle has three phases. In phase one, faculty construct an improvement plan that provides statements of areas where improvements are to be made, a timetable for achieving them, an appropriate faculty development program and, finally, identifies appropriate evaluation criteria and evidence to measure outcomes. Funding to support QILT plans is allocated by EDS from central faculty development funds. Plans are approved according to a common set of criteria that include, among others, evidence of team involvement, including students; the extent to which the proposed development lends itself to more generic applicability; and the addressing of one or more of the QAAHE core areas of provision as potential improvement areas.

Though the QILT process is the university's internal mechanism for improving quality, faculty have been guided toward the six core areas of provision. Thus, they are in a continuous and cumulative process of preparation for that exercise. Importantly, faculty are pro-actively addressing locally identified issues that can be placed in the context of the external review, rather than re-actively attempting to "defend" the subject through documentation and discussion.

Phase two represents the process of implementation and formative evaluation where the activities might include staff development workshops, the production of materials, changes in teaching methods-whatever has been identified in the plan.

Finally, in phase three, faculty evaluate whether improvements have been achieved and are effective and take action as appropriate. The outcomes of QILT improvements are then formally subjected to institutional evaluation through the annual internal departmental review.

\section{Examples of QILT Projects}

In the first year of QILT, over 50 projects were undertaken involving all departments. Some projects were vehicles for substantial change. For example, departments began to prepare distance learning materials, produce computer assisted learning $(\mathrm{CAL})$ in life sciences and mathematics, improve student feedback systems (psychology), introduce student personal profiling (a joint project), implement student self-appraisal (fashion design), and improve student handbooks in the faculty of Design, Engineering, and the Built Environment (DEBE).

In the second year, faculty responded to the early experience of QILT by specifying the criteria for acceptance of QILT proposals more precisely and by reducing the number of projects to target funding more 
effectively. The second volume of QILT reports provides evidence of continuing innovation and development. In particular the development of Instructional Technology (IT) learning resources is well-evidenced. DEBE, for example, produced a cross-departmental IT development plan. Life sciences produced a CAL package to support a skills development module, and innovation studies evaluated particular web authoring systems for distance delivery. Other important projects include English language support in DEBE, peer-assessment of practicals in psychology, and the development of a first-year computing unit in economics.

By 1997/98, budgetary constraints had curtailed the extent to which QILT funding could be made widely available. EDS decided to focus QILT projects on identified strategic objectives, partly to ensure that developments were more aligned with recently identified institutional issues related to student progression. Although this altered the essentially voluntary nature of the early delivery of QILT, it does demonstrate the way in which the process could be used to support the delivery of aspects of a university's mission or strategic plan. The prospectus for QILT in 1997/98 identified student support and guidance and the monitoring of student progression and achievement as one priority, and the use of information technology in teaching, learning, and assessment as the second. Projects were approved to create databases for monitoring student progress in several areas of the university, to develop student profiling and self-evaluation, to establish a process for identifying students' learning needs, to create a textile design database, to further develop CAL in Life Sciences, to use IT to support lifelong learning, and to develop open learning materials. These projects, and reports on their outcomes, are published and disseminated by EDS across the university in the QILT Annual Report.

\section{Overcoming Resistance-Ownership and Reward}

That the QILT process has found little political resistance in the university is interesting. It is important to try to articulate the source of that resistance and why QILT appears to side-step it. The essential elements of ownership and reward are critical to the success of QILT.

First, the ethos through which QILT is attempting to secure change is not derived from gaining agreement at committee level about policy statements, nor by managerial dictate, nor by attempting to persuade faculty of the expertise of developers. QILT attempts to secure ownership, maximum participation, and involvement in change by the university as 
a collectivity. It demands an approach that relies on teamwork and consensus, which, as Taylor and Hill (1993) have suggested, is something that is problematic in higher education:

namely, the provision of an appropriate and enriching learning experience for every student. For some establishments there may be a need to spend time reaching consensus on this point alone. This deceptively simple concept, once embraced, will effect the removal of barriers between departments, between academics and administrators arguing over points of territory or procedure and between academics entrenched in "functional foxholes" or “discipline dug-outs" (p. 24).

Whilst faculty developers ply their trade as best they can, at the institutional level wider development is often "managed" through the sector's traditional organizational structures. These structures, however, may be unsuitable for effective communication and may actually retard the process of change. Though some universities place great reliance on the democratic process enshrined in committee work or the institutional value of hierarchical management structures, the pace of change is beginning to render these organizational forms unwieldy. Both the structures, and the managerial activity emanating from them, may founder if those involved at the faculty-student interface in the institution do not have some stake in managing that change. The mistake made by the present UK administrations, and by institutions themselves, is believing that educational change can be accomplished by trying to introduce system reforms, tighter forms of planning and management, re-organization, greater accountability, and so on. All are doomed to failure if faculty do not have some stake in managing that change. It requires the empowerment of faculty to become involved in continuous improvement so that they are committed to, and own, the process of change. Of course, not all faculty will wish to take that opportunity. Many QILT projects at UEL are managed by enthusiastic faculty, whose work will nevertheless have an impact on the work of their department. Furthermore, the emphasis on a team approach means that, gradually, more reluctant faculty become involved.

Three aspects of QILT contribute to this sense of faculty ownership. First, any member of the faculty, provided a team has been identified, is entitled to submit a plan for QILT funding. The criteria for approval of plans are not based on status but simply on the efficacy (and, increasingly, the transferability) of what is proposed. Perhaps, more importantly, 
the process is based on trust. Funding is allocated on the basis of what is planned rather than the quality of the outcome or output, though progress is carefully monitored, and funding may be withheld if delivery is problematic.

Second, QILT re-conceptualizes traditional models of faculty development. It is not a skills-based, additive approach. Neither are faculty developers necessarily involved in giving expert advice to departments or individuals. QILT is simply a set of processes and procedures to enable faculty development to be embedded through a process of learning by doing. It demands an unconventional action-learning process. Though EDS also runs centrally organized faculty development sessions, these are beginning to emanate from concerns identified by faculty through the QILT process. Ownership of faculty development is clearly with faculty. Faculty are learners, actively engaged in constructing their own understanding of "development." The process has been described elsewhere (Ho, 1998) as "constructivism":

Among all the complexity, the crucial idea of constructivism is that learners are actively constructing their own understanding. In the process, the learner makes reference to his/her existing knowledge and conceptions, selects information from the perceived environment according to his/her own motives and constructs new understandings in a way coherent and useful to him/her. Learning is therefore an active constructive exercise that takes place within learners. It is not a passive receiving of ready-made authoritative knowledge impacted from without (pp. 24-25).

Third, I have also argued (Laycock, 1997) that Kolb's model of the experiential learning cycle has informed the university's QILT program both as a process for faculty development/learning and as a model for the development of a learning organization. In a knowledge-based organization it is important that such a model underpins the notion of a learning organization, and here experiential learning provides the basis for continuous learning and self-renewal. Through this conceptual model, QILT is not only a process of faculty development but also one that encourages institutional change and development. As Candy (1996) has observed: "Clearly, such work carries educational developers well beyond the threshold of simply improving teaching and learning and, indeed, beyond the bounds of staff development" (p. 10). 
In many ways the QILT process is also the institutional embodiment of Candy's (1996) ideas for the development of a learning organization in higher education in what he terms the CAREER model of faculty development, which comprises six key elements. Such a program is:

- Comprehensive. The QILT process is comprehensive and the QAAHE core areas of provision cover the majority of academic work.

- Anticipatory. QILT is a pro-active rather than re-active approach to quality improvement. The shift of emphasis towards an enhancement-led system provides the impetus for the university to anticipate change.

- Research-based. All QILT project leaders produce internal evaluative papers that are collated and disseminated by EDS annually. Some faculty have produced papers for external publication (see, for example, De Jong, 1996) or for conferences as a result of QILT projects.

- Exemplary. Many QILT projects, though they have been initiated in one department, have transferred to others. For example, the growth of study skills modular units in a number of departments has been a result of the transfer of developmental work from one department to another. Best practice has been modeled.

- Embedded. QILT is embedded in the institutional culture through the authority of the university's Quality Manual and through its reward system for staff (EDS has implemented a scheme, for example, to appoint Readers in Educational Development. Many Readers have been, or are, involved in QILT projects).

- Reflective. As a means of faculty development, QILT demands that faculty become critical and reflective analysts of their own practice.

\section{QILT-Effecting Cultural Change}

In providing a whole-institutional framework for change, the QILT process is also attempting to stimulate cultural change within the university towards a culture of quality that embraces self-critical reflection and the acceptance of responsibility for quality improvement. It is not a culture that, historically, has necessarily been firmly rooted in UK universities. 
In summarizing the debate over the rise of the quality agenda and the historical development of universities in the UK, Barnett (1992) suggests that during the period from the Middle Ages until relatively recently, universities enjoyed privileges, rights, a social independence, and societal esteem-a period of enchantment when higher education was "mysterious, an activity in which only a few were engaged, but which somehow carried its own social legitimacy. Its quality was not at issue; the activity saw itself and was seen by the host society as being self-justifying" (pp. 215-216).

This self-justifying aspect of higher education culture has come under the rigorous scrutiny of the quality microscope over the last ten years to the point where:

The host society is no longer prepared to accept that higher education is self-justifying and wishes to expose the activities of the secret garden. With greater expectations being placed on it, higher education is being obliged to examine itself or be examined by others. 'Permeability,' 'responsiveness' and 'accountability' are just some key words of the age. Against this changing mood and desire for transparency, systems of evaluation are being transported into higher education which may have a point in other spheres of modern society but which may fail to do justice to the inner activities of higher education. (p. 216)

Barnett describes this contemporary period as one of disenchantment. In part, that disenchantment is contained in faculty perceptions of the rise of managerialism (Harvey, 1995) and an attack on academic freedom or professional autonomy - an attack on the secret garden.

For the future, Barnett argues for a culture of engagement with quality:

This is not a cosy, self-satisfied state of affairs, controlled only by the academic community through its conversations. But neither is it the imposition of inappropriate technical models and systems on a distinctive form of human activity. It is judgmental, open, binding on every participant in the academic community, critical (especially self-critical), collaborative (including the students), eclectic in its approach and willing to draw on the evidence available. However, it is driven by two principal considerations: that the central activity of higher education is that of 
educating individual students; and that it is the continuous improvement in the educational processes that lies at the centre of our concerns over quality (p. 216).

Harvey (1995) suggests that there has been renewed interest in the concept of collegialism in the UK and that it "can be characterized as having taken two paths-a conservative tendency and a radical alternative." He describes the former as "cloisterism" and the latter as the "new collegialism" (p. 2). Both have emerged as a consequence of the perceived growth in managerialism but are at opposite ends of the spectrum so far as reactions to that managerialism is concerned.

A range of concepts is used to codify the cultural and educational orientations of both. Academic cloisterism is described as "inward-looking, individualistic, self-serving and self-regulating, characterized by esoteric knowledge and opacity" (p. 35). In many respects this culture carries with it the vestiges of the self-justifying nature of the culture of the enchantment period.

The new collegialism, by contrast, is said to be "outward looking and responsive; emphasizes continuous improvement; professional accountability; encourages team-working; focuses on the total student experience; views students as participants in the process of learning rather than as a customer or as an end-product; and focuses on the outcomes of higher education as well as the process" (p. 35).

\section{From Accountability to Enhancement- SEIZING THE INITIATIVE}

Through its particular ideological approach, QILT has attempted to encourage faculty toward a culture of self-scrutiny and self-improvement. In a sense, it has attempted to turn the accountability-led framework of the QAAHE Subject Review on its head. It has taken as a basic template for improvement the basis of the review, the six core areas of provision, and invited faculty to consider these in a process of continuous quality improvement rather than a one-off review exercise.

If the current emphasis on accountability is to be reviewed, some of the responsibility for effecting change at the national level must come from institutions themselves. As Harvey (1995) has argued:

In a sense, this means that initiative must be grasped via the internal initiatives. This will only be feasible with an academic body 
that is prepared to adopt new-collegiate principles of responsiveness. A cloisterist approach hands the initiative to external bodies. A new collegiate approach grasps the initiative and demonstrates that accountability is achieved through a process of continuous quality improvement (p. 40).

An institutional process such as QILT could be internally audited and a cumulative product reported to external bodies in an annual quality report. The external body could arrange a periodic audit of institutional quality improvement reports in order to validate them. A similar approach could be adopted in the US where Trow (1998), for example, has also argued for a process of audit rather than accreditation:

One answer is to urge that the regional and other accrediting bodies transform themselves or be transformed from organizations which purport to accredit the 'quality' of the institutionits teaching and learning - into bodies that have the responsibility for determining whether the institution has in place procedures and practices that enable it to learn about itself ... What the institution would be asked to report every five or ten years is evidence (largely embodied in formal procedures) that it has developed or is developing a culture of self-scrutiny and selfimprovement (p. 49).

\section{Conclusion}

I have attempted in this paper to discuss some of the more ideological purposes behind the university's QILT program rather than to evaluate its outcomes. I have argued for a more strategic, whole-institutional approach to faculty development and, thereby, the development of a culture for institutional self-improvement. QILT is a program that demands a more open, responsive, and collective approach to faculty development. In so doing it also tries to create a culture that at one and the same time urges faculty ownership, responsibility, and accountability in development, and moves toward the development of a learning organization where traditional faculty resistance is overcome.

I have further argued for a faculty development role that takes the initiative in attempting to shift prevailing accountability-led regulatory frameworks towards enhancement-led frameworks. This is not to imply that external validation of the credibility of a university's system for self- 
evaluation and self-improvement is not required. For systems to be publicly credible they need to be publicly recognizable. External bodies can provide that recognition. But continuous examination and assessment of the methods and procedures of quality assurance alone will not provide the impetus for change. A shift towards an enhancement-led system may provide that impetus and permit institutions to anticipate change.

\section{REFERENCES}

Barnett, R. (1992). Improving higher education: Total quality care. Buckingham, UK: SRHE \& Open University Press.

Candy, P. (1996). Promoting lifelong learning: Academic developers and the university as a learning organisation. The International Joumal for Academic Development, 1 (1), 7-18.

De Jong, W. (1996, July). Undergraduate mathematics: Towards a new method of teaching and learning. Paper presented at the International DERIVE and TI-92 Conference, Bonn, Germany.

Gosling, D. (1996). What do UK educational development units do? The International Jourmal for Academic Development, I (1), 75-83.

Harvey, L. (1995). Quality assurance systems, TQM and the new collegialism. Birmingham, UK: Quality in Higher Education Project Report, University of Central England in Birmingham. (ERIC Document Reproduction Services No. ED 401810 .)

Ho, A. S. P. (1998). A conceptual change staff development programme: Effects as perceived by the participants. The Intermational Journal for Academic Development, $3(1), 25-38$.

Jackson, N. (1997). Academic regulation in UK higher education: Part II-typologies and frameworks for discourse and strategic change. Quality Assurance in Education, 5(3), 165-179.

Jenkins, A. (1996). Discipline-based educational development. The International Journal for Academic Development, 1 (1), 50-62.

Laycock, M. (1997). QILT: A whole institutional approach to quality improvement in learning and teaching. In S. Armstrong, G. Thompson, \& S. Brown (Eds.), Facing up to radical changes in universities and colleges (pp. 75-83). London, UK: Kogan Page.

Taylor, A., \& Hill, F. (1993). Quality management in education. Quality Assurance in Education, 1 (1), 21-28. 
Trow, M. (1996). Trust, markets, and accountability in higher education: A comparative perspective. Higher Education Policy, 9 (4), 309-324.

Trow, M. (1998). On the accountability of higher education in the United States. In W. G. Bowen \& H. T. Shapiro (Eds.), Universities and their leadership (pp. 15-64). Princeton, NJ: Princeton University Press.

Yorke, M. (1994). Enhancement-led higher education. Quality Assurance in Education, 2 (3), 6-12.

\section{Contact:}

Mike Laycock

Educational Development Services

University of East London

Longbridge Road

Dagenham

Essex RM8 2AS

UK

(0) 1818493436

(0)181 8493524 (FAX)

m.j.a.laycock@uel.ac.uk

Mike Laycock is a Principal Lecturer at the University of East London. In addition to coordinating the Quality Improvement in Leaming and Teaching (QILT) program in Educational Development Services, he is also Director of the University's Work-based Learning Unit, which offers a cross-institutional MA/MSc/ PGDip by Work-Based Learning. Former posts at the University have included Course Director of undergraduate and, then, postgraduate programs by independent study, and Director of the University's Enterprise Learning Program (funded by the DfEE). He has been a frequent presenter on higher education issues at national and international educational development conferences. He is also a member of the SEDA (Staff and Educational Development Association) Executive. Current research interests include a US/UK comparison of strategic planning in higher education institutions. He holds an MPhil from the University of East London.

The QILT Handbook (1995) and QILT Improvement Plans/Reports (1995, 1996, 1997) are available from the QILT Unit, University of East London, Longbridge Road, Dagenham, Essex RM8 2AS, United Kingdom. 